\title{
Relationship between globalization and internationalization of higher education
}

\author{
Wadim Strielkowski ${ }^{1 *}$, Veronica Grebennikova ${ }^{2,3}$, Elena Razinkina ${ }^{4}$, and Ekaterina Rudenko ${ }^{2}$ \\ ${ }^{1}$ University of California, 303 Giannini Hall, CA 94720, Berkeley, United States \\ ${ }^{2}$ Kuban State University, 149 Stavropolskaya str., Krasnodar, 350040, Russian Federation \\ ${ }^{3}$ Griboyedov Institute of International Law and Economics (IMPE named after A. S. Griboyedov), 21 \\ Entuziastov highway, Moscow, 111024, Russian Federation \\ ${ }^{4}$ Peter the Great St.Petersburg Polytechnic University, 29 Polytechnicheskaya st., St.Petersburg, \\ 195251, Russian Federation
}

\begin{abstract}
Our paper examines the relationship and differences between internationalization and globalization in contemporary development of higher education. Internationalization and globalisation are perceived as central realities of the influence of the $21^{\text {st }}$ century on higher education. Moreover, internationalisation and globalisation work together to transform the self-image and organisational activities of research universities and adult education centres. Some even go as far as to claim that the globalization process has produced a new grand model of global universities. We argue that globalization and internationalization of higher education help to bring talents, increase the balanced economic and scientific potential of a given country and shape up the human capital leading to the sustainable economic growth. However, the recent situation with the COVID-19 pandemic puts all these favourable outcomes under threat. More than 1.1 million international students were enrolled in United States colleges in the 2019-2020 school year. After decades of steady growth, that means a decline of nearly 20000 international students per year. Our study examines against this background the differences between internationalization and globalization in the contemporary development of higher education. We discus the current and future developments of the globalization and internationalization of higher education and make predictions on their impacts on the universities in the United States and other countries.
\end{abstract}

Keywords: higher education, internationalization, globalization, concentration points.

\section{Introduction}

Globalization is part of the twenty-first century reality in the context of economic and academic trends. However, one has to realize that globalization and internationalisation of higher education (HE) proceed hand in hand as a result of these trends [1].

One can start with the explanation of globalization, arguing that internationalization is both a response to globalization and a factor that helps to facilitate it. Many of the activities

\footnotetext{
${ }^{*}$ Corresponding author: strielkowski@berkeley.edu
} 
now carried out towards the internationalisation of higher education do not address the possible negative consequences of this process [2]. Internationalisation takes place at universities while globalization takes place outside of them [3]. Scientists claim that the globalization process is a force as powerful as industrialization, urbanization and secularization grouped together. The higher education system and individual higher education institutions are now being called upon to strike a delicate balance between respecting national priorities and local needs while adapting to operate in an international environment $[4,5]$.

When we discuss best practices for teaching globalization and how to communicate them best to students who are experiencing it, it goes without saying that university students should take advantage of study abroad and international internship and research opportunities [6]. Faculty should create a sustainable network of foreign universities for education and research to offer their students the options available. Another good practice is the possibility for students who speak at least one foreign language (in Europe it is common to speak more than one language, but this is not common in the United States where only Spanish is gaining some popularity due to the increasing number of migrants from Latin America) and graduate programs for students to benefit by enrolled at a foreign university and seeking a dual degree that matches the university you are attending. Such differentiation is vital given the trends and challenges in the higher education sector [7]. The core jobs of colleges and universities are teaching, research, and services. Higher education institutions want to offer pleasant experiences, courses and student services that are indispensable and closely linked to physical and mental health. The increase in young people enrolling in secondary, postsecondary and postgraduate education, the increasing urbanization of developing countries and the rise of new middle-income countries seeking to improve their economic competitiveness require a comprehensive and holistic strategy focused on the effective implementation of the entire system $[8,9]$. These challenges must be solved through the collection and exchange of knowledge between disciplines, institutions and other institutions at global level. Achieving these objectives requires defining governance, management and strategic leadership in higher education and other areas of public management. Tertiary education is crucial to the improvement of primary and secondary education, as tertiary institutions prepare teachers, administrators, executives and other education professionals to create policies and structures for young children $[10,11]$.

The sudden shock of COVID-19 pandemic has forced tertiary education systems with different experiences around the world to adapt to new areas of technology, local provision, teaching and research. By exploring these new trends, new facets of higher education and research gain additional importance in the $21^{\text {st }}$ century globalised world $[12,13]$. This COVID-19 impact coupled with an ongoing globalization had a profound impact on higher education and research.

The strength of today's economy is built on the use of knowledge and expertise, and the role of the higher education system has become crucial for international competition [14]. International mobility in higher education has led to a new form of competition in higher education research: economic competition plays a key role in this sector, while competition between academic and research institutions is hampered by their concentration, diversification and modernisation [15]. Furthermore, it is likely that globalization and the fourth industrial revolution in technology will further affect higher education for the foreseeable future. Higher education institutions must respond to this pressure by working towards globalisation and internationalisation [16].

In addition, it can be noted that in the recent years, globalisation has led to unprecedented changes in all areas of economy and environment, from how we do business to how we interact with media [17]. By linking technology, travel and new industries, the world has become a smaller place. The internationalisation of higher education is a response to and 
result of this globalisation and the internationalisation of higher education. For universities to be able to better prepare students for developing careers, universities must be aware of globalization and internationalisation's trends, opportunities and experiences. Colleges and universities today have the opportunity to think differently and help students build skills and networks for success. It is impossible to look into a crystal ball and predict the future, but if the experience of the past decade is a harbinger of the future, competition for the brightest students and scientists is likely to increase, with benefits for some countries and higher education institutions and losses for others [18]. Several countries are already investing in important marketing campaigns to attract the best and brightest talent to study and work at their institutions, to provide the brainpower for innovation and research initiatives and to not underestimate the complexity and challenges associated with the mobility of academics and professionals [19].

Technology and social networks will provide new opportunities for brain sharing and mitigate the overall effects of winners and losers as the current obsession with global rankings and economic competitiveness agendas suggests. Some authors argue that higher skills in soft skills and hard skills are not enough, and that higher education must go further to change attitudes and behaviours that are at the heart of a globalized knowledge economy [20]. With regard to this, Hess [21] distinguishes between two types of educational reformers: status reformers who do not challenge state education control with common sense and reformers who prefer a non-bureaucratic education system governed by market competition and subject to accountability as comparable to that of ordinary business. Having this in mind, it can be stated that the American education system prepares students for the job market and the social roles that must be fulfilled. In practice, this theory is applied in Finland, which has transformed the education system with degrees considered the best in the world [22, 23]. There is little scope to raise tuition without jeopardizing other sources of revenue, such as sports and research funding, so education policymakers must ask themselves whether to reassess education spending and redistribute existing resources (for example tackling the questionable systems of renumerations for publications [24]). Colleges and universities need to rethink their business models and consider new ways to operate independently or in partnerships to achieve the same goals at a lower cost. There is also the possibility and need to rethink the funding of higher education so that students do not sink into debt [25]. The estimated increase of 120 million higher education students represents a possible change of $51 \%$ in terms of the growing number of international students [26]. The rise of anti-immigrant policies in many developed Western economies, combined with the need to increase enrolment, mean that institutions need to find new ways to attract international students.

Based on global demographic trends, one can predict that more people would be moving to larger conurbations, creating a greater need to balance education and employment. The role of universities and colleges in local economic development will become more important through partnerships between industry and institutions as cities continue to grow as job and career centres. It is also apparent that higher education will have to adapt to regional needs.

\section{Internalization of higher education}

Addressing global challenges requires cooperation that goes beyond governments, and universities must mobilize innovative intellectual resources to develop solutions and strategies. Internationalisation and globalisation are working towards creating global interdependence in business, politics and culture based on the revolutions in transport and communication technology [27].

Today, universities are gaining the ability to change self-image and organizational activity through research at university and adult education centres. While globalization is a process focusing on the worldwide flow of ideas, resources, people, economies, values, 
cultures, knowledge, goods, services and technologies, internationalization in higher education describes the process of integrating the international, intercultural and global dimensions and goals of the educational, learning, research and service functions of the university and the higher education system. The differences between the concept of global flow and the concept of the relationship between nations are striking and deep. Internationalization emphasizes the relation between nations, peoples, cultures, institutions and systems, while globalization emphasises concepts of global flows of economies, ideas and cultures. This can be shown on the growing numbers of international student mobility (Figure 1) that originates mostly from the countries like China or India.

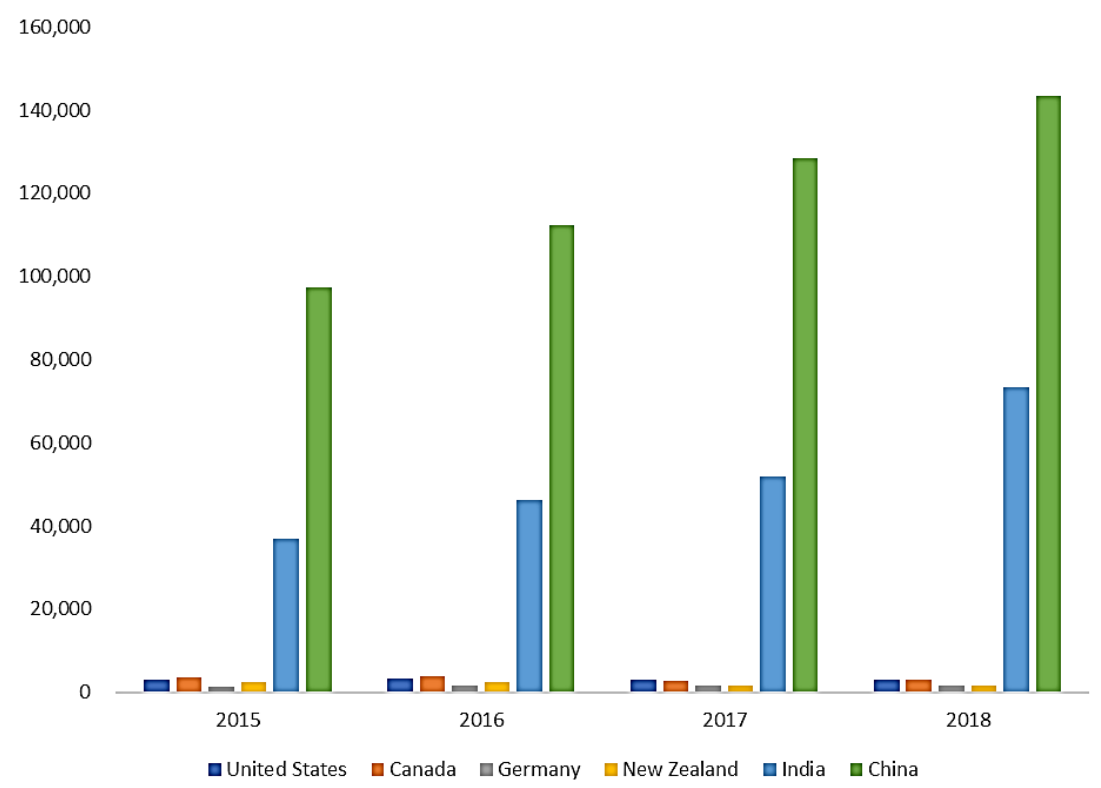

Fig. 1. International student mobility.

Source: [28]

Globalisation has led to unprecedented changes in all aspects of the economy and the environment in recent years, from business to media interactions. Higher education institutions (both public and private) are becoming global actors, following trends found in many other sectors. A study by Nielsen suggests that internationalization should be viewed as a leading variable that encourages and facilitates globalization, not as a response variable that describes how institutions respond to globalization in economic, political, cultural and social interaction [29]. Internationalisation has increased in scope, scope and significance in the course of several decades of intensive development. The challenges and the complex interplay between globalization and internationalisation as well as the diverse ways in which higher education institutions are involved and represented in the study of higher education systems and the position of national and national borders are becoming increasingly clearer. Analysis of the recent trends shows that the flow of international students has become more unstructured and centralized. For example, four decades ago, there were barely any foreign students in United States colleges and universities. However, international student flows have significantly increased and exceeded the 3 million marks in 2009 [30]. Extensive data on mobility provide unique insights into the global education process. At advanced levels, brain increases are particularly high: $24 \%$ of doctoral students come from international OECD countries and an average of $9 \%$ from abroad. Most of the doctoral training is offered by a 
few institutions in the United States and the United Kingdom, which together account for more than $50 \%$ of international doctoral students [31]. Competition focuses on STEM (science, technology, engineering and mathematics) as these areas are considered crucial to innovation, technological progress, industrial performance and economic growth. The United States has almost half of all its international Ph.D. candidates in STEM, international students make up more than $40 \%$ of all doctoral applications in the UK and Switzerland, and the Netherlands has a particularly strong concentration in these areas [32]. Regardless of the motives behind internationalisation policy of higher education, shift in economic orientation and results, internationalisation activities will continue to have a broad impact and generate cosmopolitan roots in higher education. The type of internationalization activities that nations and institutions can pursue will determine their position in the global high education landscape.

\section{Economic globalization is the basis of HE internationalization}

One of the excellent examples of the economic globalization being the basis of HE internationalization is European Union. According to the European Universities Initiative [33], the links between European universities should be strengthened improving the possibility of confessional diplomas for educated people and encouraging free movement of students and scientists. Globalisation, integration and the internationalization of education have been fundamental global trends in the last decade [34]. A new objective is training of professionals able to work with the changing conditions of the global market by receiving higher education in the process of globalisation and internationalisation of the economy and economy. The internationalization of education in a vast number of countries has become the target of the policy on the part of the state, which determines some national political and economic problems. Higher education institutions, both public and private, are becoming global actors following trends seen in many other sectors [35]. As a result, the influence of globalisation and internationalisation on the character and behaviour of universities has become a central theme of many recent studies [36].

In broader terms, internationalization is a both a response to globalization and a factor contributing to facilitating it. The same conflict arises with regard to the impact of globalization on the appropriate response of academic institutions to globalisation. The only obvious consensus among contemporary researchers is that globalization affects universities because they are involved in promoting globalization. Growing unease, stemming on the one hand from a strong commitment to the ideal of internationalization to improve academic quality and international understanding and benefiting from a variety of perspectives and cultural traditions, and on the other hand from vocal criticism of the internationalization process which leads to commodification, increased brain drain and reduced diversity in higher education often pose serious questions and issues for internationalization. Thence, one needs to examine the evolving process of internationalization, its many benefits and potential negative impacts and outline how institutions can refocus the process on academic foundations. Internationalisation of higher education is a dynamic process shaped by the international context in which it takes place. Internationalization is the same as globalization, but globalization is only the second approach to globalization. Corresponding international standards include, for example, foreign work carried out by foreign partners. National excellence programs increase differentiation in higher education by paying more attention to a small number of international and world-class universities, while national, regional and flagship institutions compete with other institutions for talent, ranking in global rankings, access to influential journals and funding costs [37]. It may be said that globalization is globalizing, but it is different from globalization. In today's global knowledge society, the concept of internationalization of higher education as it becomes increasingly globalized 
requires further consideration of its impact on policy and practice, as more countries and types of institutions around the world participate in this process. Internationalization is no longer seen in the sense of a Westernized, Anglo-Saxon, English-speaking paradigm [38].

\section{The role of higher education in bringing talents}

In publications since the $1970 \mathrm{~s}$, the use of internationalisation in relation to higher education has been observed. One can assume that the awareness of result awareness in higher education in general has increased in recent decades and has shaped discourses on the value of internationalization. The concept of comprehensive internationalisation was also developed [39].

A growing competition in higher education and commercialisation and an increase in cross-border providing of higher education call into question the value attached to cooperation in the form of exchange programmes and partnerships. At the same time, the internationalisation of curricula, teaching and learning processes, often referred to as internationalization at home, is losing relevance as the traditional focus on mobility of qualifications and mobility within the framework of home qualifications. Post-secondary schools should promote interaction between international and domestic students in order to develop their cultural skills in preparation for a globalised future. Although cross-border knowledge transfer is often taken for granted in higher education as a key element of internationalization, it has been highlighted in recent public debates, particularly since student mobility became a prominent issue in this area in the 1980s and 1990s. For example, the success story of the Erasmus + programme that supports temporary student mobility throughout Europe and the emphasis on student mobility as the main objective of the Bologna reform process highlight the key role of student mobility in Internationalisation policies and activities in Europe [40]. The rise of international students in post-secondary institutions will result in teachers adapting their teaching styles and content delivery to the different needs of students and language deficits in the classroom. Tertiary education is crucial to improve primary and secondary education as it prepares teachers, administrators, executives and other education experts to develop policies and personnel schools for young children. Achieving these objectives requires defining governance, management and strategic leadership in higher education and other areas of public management.

It appears that the internationalization of higher education lies in the theory and process of integrating the international, intercultural and global dimensions of the purpose, function and provision of postsecondary education. Recent (and still ongoing) COVID-19 pandemic forced segments of tertiary education systems around the world with different experiences to adapt to new areas of technology and local provision of education and research. It is now important to assess these challenges and outline how institutions can refocus higher education toward internationalization as an academic foundation. One can acknowledge the significant benefits of internationalisation in higher education but also draw attention to the negative and unintended consequences of such a view and warns higher education institutions of the need to ensure that internationalisation results have positive reciprocal benefits for them and the countries concerned. The ideal rationale for internationalisation of higher education is to create a more democratic, just and equal world in terms of international cooperation. In this phase, the goal of recruiting international students is to strengthen academic, cultural and educational exchanges with foreign countries and to improve the international competitiveness of local universities [41]. For that, universities worldwide should establish budgets to encourage international communication and cooperation and improve the international environment. An increasing number of future Asian international students continue to value quality of education and tithe career support, reputation of universities and employers when they select universities to which they wish to apply. In addition, innovations 
in the high school reform, research, analysis, operationalization of education reform, and promotion of best practices and evidence-based decision-making supported by international perspectives and comparative studies should be supported without disruptions. In order to address these issues, we must shift the boundaries of our own thinking and thinking of the others, focus on people and ensure that they develop and demonstrate institutions that represent human values, which require new quantitative and qualitative measures.

\section{Conclusions}

The recent changes in the internationalization of higher education are subjected to issues such as COVID-19 restrictions. Many universities have lifted quotas limiting the number of foreign students. On the other hand, a significant number of other countries have encouraged their universities to increase their number of foreign students and exchange students not only to increase university revenues but also to cultivate soft power and to increase international trade with other countries. By building and maintaining strong international partnerships, higher education institutions can offer their students more affordable study opportunities that meet their academic needs. International partnerships can also help colleges and universities build global campuses and prepare students for working in different countries, cultures and languages. Study partnership opportunities also open the door to a wider international exchange of research ideas and best practices between institutions. International partnerships between partner universities can strengthen higher education and scientific research in developing countries and work to prevent the brain-drying phenomenon that is often accompanied by the exchange programmes. Links can be established between higher education institutions and spurring the exchange of ideas and information around the world. International understanding and development should be promoted to improve higher education in low-income countries.

The goal of the successful internationalization of HE is fulfilled when international students have a positive experience in the country they are visiting. Full-time international exchange students become natural ambassadors in this case when they stay in the host country and return to their home country. Furthermore, the experiences of students participating in exchange programmes with universities in developing countries have long-term implications for political institutions and influence the political behaviour of their home countries in a positive direction. With regard to the above, it is good to examine the traditional understanding of government-funded student exchange programs, programs such as Fulbright in the United States, academic exchanges and labour relations between universities and think tanks that flourished in recent years, and technical education programs like Global Ties, which have helped build capacity and the rule of law in Mexico with government support. These student-oriented programs are only a component of an approach to international exchange deeply rooted in our hemisphere. The contacts and language skills of American students studying in these regions have helped the United State economy and opened new opportunities for United States investment in the region. This is one of the best and most cost-effective ways to build educational exchanges. This is happening while other countries are pursuing policies aimed at expanding their own exchange programs in the field of education. Universities in Switzerland, Hong Kong, Singapore and the United Kingdom host communities of students and scientists from around the world and they solve some of the most pressing problems in the world through research. All of the four countries above have the world's most international universities. These international universities have the highest proportion of international students and staff working with scientists around the world and a strong global reputation to match.

Although HE economic contributions tend to take centre stage in the country, they also bring cultural, political and historical perspectives with them that contribute to building a 
vibrant and diverse campus community. The international student body at the colleges and universities worldwide is subject to the same legal and regulatory restrictions. Despite the huge diversity of student population, there are significant differences in language proficiency, family income and educational goals.

Many studies have examined the challenges and barriers faced by international students at colleges and universities in other countries. These challenges include language difficulties, difficulties in adapting to academic culture, misunderstandings, complications in communicating with teachers and peers, stress, anxiety, feelings of isolation from social experiences, culture shock, financial hardship, lack of adequate housing, isolation and loneliness and the adjustment to their daily lives. For most international students attending a university or college in a foreign country, there can be an overwhelming change in life and culture. Nevertheless, we can state that the gains from this international experience surpass any difficulties and negative externalities for they provide new insights and novel ideas that are very important for the sustainable economic growth and development of the societies worldwide.

\section{References}

1. B. Barrett, Globalization and change in higher education: The political economy of policy reform in Europe (2017)

2. M. Tight, Research Papers in Education, 36(1), 52-74 (2021)

3. H. Ota, Educational Studies in Japan, 12, 91-105 (2018)

4. A. Remache, A. Belarbi, International Journal of Economic Policy in Emerging Economies, 12(3), 264-284 (2019)

5. W. Strielkowski, V. Volchik, A. Maskaev, P. Savko, Economies, 8(2), 27 (2020)

6. T. Curtis, J. Ledgerwood, Journal of International Education in Business, 11(1), 63-78 (2018)

7. A. Thompson, The Modern Language Journal, 101(3), 483-500 (2017)

8. W. Strielkowski, Science, 360(6384), 27 (2018)

9. A. Lavecchia, P. Oreopoulos, R. Brown, American Economic Review: Insights, 2(2), 209-224 (2020)

10. A. Abdulrahman, X. Hui, X. International Journal of Secondary Education, 6(3), 46-53 (2018)

11. F. Díez, A. Villa, A. López, I. Iraurgi, Heliyon, 6(4), e03824 (2020)

12. N. Al-Kumaim, A. Alhazmi, F. Mohammed, N. Gazem, M. Shabbir, Y. Fazea, Sustainability, 13(5), 2546 (2021)

13. W. Strielkowski, Preprints, 2020040290 (2020)

14. R. Malik, Journal of Sustainable Development Education and Research, 2(1), 9-20 (2018)

15. C. Musselin, Socio-Economic Review, 16(3), 657-683 (2018)

16. H. Bradford, A. Guzmán, M. Trujillo, Journal of Higher Education Policy and Management, 39(4), 435-452 (2017)

17. I. Cabelkova, W. Strielkowski, M. Mirvald, Transformations in Business and Economics, 14(1), 65-75 (2015)

18. K. Miller, G. Sonnert, P. Sadler, International Journal of Science Education, Part B, 8(2), 95-114 (2018) 
19. W. Li, K. Bakshi, Y. Tan, X. Huang, International Migration, 57(3), 373-391 (2019)

20. S. Urmetzer, J. Lask, R. Vargas-Carpintero, A. Pyka, Ecological Economics, 167, $106435(2020)$

21. F. Hess, Common sense school reform (2015)

22. K. Määttä, S. Uusiautti (eds.), Early child care and education in Finland (2014)

23. T. Takala, J. Tikkanen, A. Haapala, S. Pitkänen, P. Torssonen, R. Valkeavirta, T. Pöykkö, Journal of Cleaner Production, 221, 176-188 (2019)

24. W. Strielkowski, Nature, 544(7651), 416 (2017)

25. J. Martin, J. Samels, Consolidating colleges and merging universities: New strategies for higher education leaders (2017)

26. R. Choudaha, Studies in Higher Education, 42(5), 825-832 (2017)

27. T. Hussain, J. Eskildsen, R. Edgeman, M. Ismail, A. Shoukry, S. Gani, Sustainability, 11(19), 5242 (2019)

28. OECD, https://data.oecd.org/students/international-student-mobility.htm (2021)

29. S. Nielsen, https://escholarship.org/uc/item/8qf1g31h (2011)

30. S. Brint, Two cheers for higher education: Why American universities are stronger than ever-and how to meet the challenges they face (2019)

31. A. Vega-Muñoz, P. Gónzalez-Gómez-del-Miño, J. Espinosa-Cristia, Sustainability, 13(6), 3195 (2021)

32. C. Amuedo-Dorantes, D. Furtado, H. Xu, Labour Economics, 61, 101752 (2019)

33. European Universities Initiative, https:/lec.europa.eu/education/education-in-theeu/european-education-area/european-universities-initiative_en (2019)

34. P. Terem, P. Čajka, L. Rýsová, Economics and Sociology, 8(2), 154-171 (2015)

35. R. Baltaru, Y. Soysal, Higher Education, 76(2), 213-229 (2018)

36. Y. Guo, S. Guo, Studies in Higher Education, 42(5), 851-868 (2017)

37. M. Altin, Athens Journal of Education, 6(3), 237-256 (2019)

38. H. de Wit, P. Altbach, Policy Reviews in Higher Education, 5(1), 28-46 (2020)

39. M. Chou, P. Ravinet, Policy and Society, 36(1), 143-159 (2017)

40. Z. Horváthová, A. Čajková, Integration of Education, 22(3), 412-425 (2018)

41. M. Wihlborg, S. Robson, European Journal of Higher Education, 8(1), 8-18 (2018) 